\title{
Heterogeneity in Past Year Cigarette Smoking Quit Attempts among Latinos
}

\author{
Daniel A. Gundersen, ${ }^{1}$ Sandra E. Echeverria, ${ }^{2}$ M. Jane Lewis, ${ }^{3}$ Gary A. Giovino, ${ }^{4}$ \\ Pamela Ohman-Strickland, ${ }^{5}$ and Cristine D. Delnevo ${ }^{3}$ \\ ${ }^{1}$ School of Nursing, University of Medicine \& Dentistry of New Jersey, 65 Bergen Street, Room GA-225, Newark, \\ NJ 07101-2012, USA \\ ${ }^{2}$ Department of Epidemiology, School of Public Health, University of Medicine \& Dentistry of New Jersey, 683 Hoes Lane West, \\ Piscataway, NJ 08854, USA \\ ${ }^{3}$ Department of Health Education and Behavioral Science, School of Public Health, University of Medicine \& Dentistry of New Jersey, \\ 683 Hoes Lane West, Piscataway, NJ 08854, USA \\ ${ }^{4}$ Department of Community Health and Health Behavior, School of Public Health and Health Professions, University at Buffalo, \\ The State University of New York, 310 Kimball Tower, Buffalo, NY 14214-8028, USA \\ ${ }^{5}$ Department of Biostatistics, School of Public Health, University of Medicine \& Dentistry of New Jersey, 683 Hoes Lane West, \\ Piscataway, NJ 08854, USA
}

Correspondence should be addressed to Daniel A. Gundersen, gunderda@umdnj.edu

Received 2 December 2011; Revised 6 March 2012; Accepted 6 March 2012

Academic Editor: Lorraine Greaves

Copyright (C) 2012 Daniel A. Gundersen et al. This is an open access article distributed under the Creative Commons Attribution License, which permits unrestricted use, distribution, and reproduction in any medium, provided the original work is properly cited.

Objective. Examine the association between English language proficiency (ELP) and immigrant generation and having made a cigarette smoking quit attempt in the past 12 months among Latinos. Examine if gender moderates the association between acculturation and quit attempts. Methods. Latino past year smokers from the 2003 and 2006/07 Tobacco Use Supplement to the Current Population Survey were analyzed. Logistic regression was used to examine the association between quit attempt and ELP and immigrant generation, controlling for demographics and smoking characteristics. Results. Latinos with poor ELP were more likely to have made a quit attempt compared to those with good ELP (adjusted odds ratio $[\mathrm{AOR}]=1.22$, confidence interval [CI]: 1.02-1.46) after controlling for demographic and smoking characteristics. First (AOR = 1.21, CI: 1.02-1.43) and second generation immigrants $(\mathrm{AOR}=1.36, \mathrm{CI}: 1.12-1.64)$ were more likely than third generation immigrants to have made a quit attempt in the past 12 months. Conclusion. Quit behaviors are shaped by differences in language ability and generational status among Latinos. This underscores the need to disaggregate Latinos beyond racial/ethnic categories to identify subgroup differences relevant for smoking and smoking cessation behaviors in this population.

\section{Introduction}

Research on cigarette smoking among Latinos has explored differences with respect to acculturation [1-14], that is, "the process by which groups or individuals integrate the social and cultural values, ideas, beliefs, and behavioral patterns of their culture of origin with those of a different culture" [15]. Acculturation has been conceptualized and measured several ways, but public health research has typically included items on language preference and proficiency and the extent of contact with coethnic members, although more recent work has challenged this limited view of acculturation processes
[16]. In general, this research has demonstrated that Latinas with higher levels of acculturation are more likely to smoke than Latinas with lower levels of acculturation $[1,3,4,6,8-$ 12 , 14], though two studies found no association $[7,13]$. Among men, however, the evidence generally finds no association $[4,7,9,12-14]$, and among the studies where a significant association was found the results were inconsistent $[6,8,10]$.

The research on patterns of cigarette smoking among Latinos has largely focused on current smoking and differences in prevalence. However, prevalence is influenced by both initiation and cessation, and it is imperative for public 
health to understand the patterns of these behaviors as well. In particular, calls have been made to better understand cessation behaviors among racial/ethnic minorities $[17,18]$. While some research has examined differences relative to non-Latino whites [19-24], very few studies have examined the role of acculturation in cessation behaviors. The research that has been published has relied on community or intervention studies based on nonprobability samples, and have produced inconsistent findings $[17,25,26]$. Moreover, ignored in the studies of acculturation and tobacco use and cessation is an examination of intermediate cessation behaviors, including quit attempts.

The lack of knowledge of the patterns of cessation behaviors among Latinos is cause for concern, particularly given the growth of this population in recent decades [27]. Additionally, Latinos are a heterogeneous population with varying health profiles. One striking characteristics is that roughly $40 \%$ is foreign born (approximately 30\% excluding Puerto Rico) [28], a feature the tobacco industry has already recognized and incorporated it into their marketing practices [29]. Moreover, the USA Census Bureau estimates Latinos to be the fastest growing racial/ethnic group in the U.S.-projecting it will comprise about $25 \%$ of the total population by 2050 , and net migration likely will play an important role in this growth $[27,30]$. As such, it is crucial for tobacco behavior research to focus on all aspects of tobacco use behaviors and not just prevalence in this population.

The aim of this paper is to describe population level differences in cigarette smoking quit attempts among Latinos, with a focus on two measures often included in acculturation research-English language proficiency (ELP) and immigrant generation. In addition, we explore whether gender moderates the association between quit attempts and ELP or immigrant generation.

\section{Methodology}

2.1. Data Sources and Sampling Design. Data from the 2003 and 2006/07 Tobacco Use Supplement (TUS) to the Current Population Survey (CPS) were analyzed [31-34]. Details on the TUS-CPS methodology are described elsewhere [3134]. Briefly, the TUS-CPS is a national survey of tobacco behaviors which employs a multistage probability sampling design [34]. The self-response rates ranged from $61 \%$ to $65.8 \%$ for the waves analyzed in this paper $[32,33]$. The analysis was restricted to 4,589 adult ( $\geq 18$ years of age) Latino current smokers and smokers who quit in the past 12 months (i.e., past year smokers). Proxy responses, persons under the age of 18 , and those indicating they have never been regular smokers were excluded.

\subsection{Variable Selection and Operationalization}

2.2.1. Outcome. The outcome was having made a quit attempt in the past 12 months (yes $=1$, no $=0$ ). Quit attempts were operationalized as, in the last 12 months, having stopped smoking for 1 day or longer because he/she was trying to quit smoking, having made a serious attempt to stop smoking because he/she was trying to quit even if he/she stopped for less than one day or having successfully stopped smoking.

2.2.2. Focal Independent Variables. English language proficiency was dichotomized into "poor" versus "good" English ability. Respondents who conducted the interview in Spanish or another non-English language were assumed to have poor English language proficiency, while those who conducted the interview in English were assumed to have good English language proficiency. This is a proxy measure of language proficiency that has shown good agreement with the acculturation scale in the National Alcohol Survey (kappa $=.71)$ [35].

Immigrant generation was categorized to contrast first generation (foreign born individuals), second generation (USA born, with at least one foreign born parent), and third generation or higher (USA born, with 2 USA born parents; hereafter referred to as third generation).

2.2.3. Control Variables. Control variables were selected based on previous empirical evidence in the tobacco control literature or the literature on Latino health. Sociodemographic control variables include education (less than high school, high school or GED, some college, or bachelor's degree or higher), annual household income (less than $\$ 25 \mathrm{~K}$, $\$ 25 \mathrm{~K}$ to less than $\$ 50 \mathrm{~K}, \$ 50 \mathrm{~K}$ to less than $\$ 75 \mathrm{~K}$, and $\$ 75 \mathrm{~K}$ or more), and gender.

Age of smoking initiation and time to first cigarette in the morning were included to account for smoking behaviors and dependence. Age of initiation was categorized as "before 18," "18 to 24," and "25 years and older." Time to first cigarette after waking was categorized as "less than 30 minutes," "30 minutes or more," and "varies." Having received advice from a health care provider to stop smoking in the past 12 months was coded as "yes" versus "no". Respondents without a health care visit in the past 12 months were regarded as not having received advice to stop smoking. Lastly, per capita tobacco control expenditures were included to control for the tobacco control context in which the respondents live. Following Farrelly et al. [36, 37] tobacco expenditures were computed to include $100 \%$ of the current year (i.e., year of data collection) per capita funding while discounting the three most previous years by $25 \%$ per year.

In addition to the variables described above, race, country of origin, and occupation type were included in the multivariable models if they met the criteria suggested by Hosmer and Lemeshow [38].

2.3. Statistical Analysis. Overall associations were estimated by fitting multivariable logit models, where log-odds of a quit attempt in the last 12 months was regressed on the focal independent variables and a set of control variables, with separate models for ELP and immigrant generation. Fitting separate models for ELP and immigrant generation was done to recognize that language proficiency is likely an intermediate variable between immigrant generation and the outcome, rather than the two focal independent variables being treated as confounders. Age was centered at the mean 
in the sample and cumulative per capita tobacco control funding was centered at the mean among states. Additionally, an interaction term for age of initiation and age was included to control for the differing effect age of initiation may have by age of respondents.

To assess whether gender moderates the focal relationships, product terms for gender and ELP and gender and immigrant generation were added to the respective models. The interactions were examined using the approach described by Norton et al. [39] and Ai and Norton [40]. However, the conclusion of the interaction analyses was consistent across the range of predicted probabilities. As such, for succinctness only the exponentiated logit coefficient for the interaction terms are presented and discussed in this paper.

The CPS is released with pre-imputed demographic information for some variables with missing values. The imputation methods for these variables are described elsewhere [34]. Categorical variables that were not pre-imputed were coded to include an "unknown" category and included in the models. One exception is for ELP, which had less than half a percent of observations missing.

All analyses were conducted in Stata 11 [41]. Sampling weights and balanced repeated replication weights (240 replicates) with Fay's adjustment factor were used to adjust the point and interval estimates for the complex survey design. Because the objective of the analysis was to describe population level patterns in quit attempts, 95\% confidence intervals are presented and discussed rather than $P$-values. This allows for an assessment of the range of plausible values rather than using a testing approach for between group differences. Readers interested in assessing statistical significance can do so using the conservative approach of judging non-overlapping confidence intervals between groups [42].

\section{Results}

3.1. Sociodemographic Description. Table 1 provides univariate and bivariate descriptive statistics of the sociodemographic characteristics of Latino past year smokers in the study sample. Overall, about three out of four Latino past year smokers had good ELP and almost half were first generation immigrants. Nearly two-thirds of the respondents were male, and the mean age was 38 years. Less than ten percent had a bachelor's degree or higher while seven out of ten had either less than a high school education or a high school diploma or equivalent. About one in ten had an annual household income of $\$ 75,000$ or more while over four in ten reported a household income of less than $\$ 25,000$ annually. Almost three out of ten reported having a manual labor occupation, less than one in ten were unemployed, and two in ten were not in the labor force. Nearly six in ten reported Mexico as their Latino origin, while fifteen percent reported Puerto Rico, less than five percent reported Cuba. Finally, nine out of ten were white, while the rest were black or some other race.

Compared to Latinos with good ELP, those with poor ELP were more likely to be first generation immigrants, slightly older, male, have less than a high school education, have an annual household income less than $\$ 25,000$, report Mexico as their country of origin, and identify themselves as white. Those with poor ELP were less likely than those with good ELP to have a management occupation and report Puerto Rico as their country of origin.

First generation immigrants were less likely than second and third generation immigrants to have good ELP, and have annual household income of at least $\$ 75,000$. However, first generation immigrants were more likely than second and third generation immigrants to be male and have less than a high school education.

\subsection{Smoking Characteristics of Latino Past Year Smokers.}

Table 2 presents univariate and bivariate descriptive statistics of the smoking characteristics of the Latino past year smoker population. Overall, just over half had made a quit attempt in the past year, about half began smoking regularly before their 18th birthday, two out of ten smoked their first cigarette within 30 minutes of waking in the morning, and three of ten reported having received advice to stop smoking from a health care provider in the past 12 months. Lastly, over half were current daily smokers, three in ten current someday smokers, and just over one in ten had stopped smoking in the 12 month period prior to the time of data collection.

Those with poor and good ELP were about equally likely to have made a quit attempt in the past 12 months. Second generation immigrants were more likely than third generation immigrants to have made a quit attempt. Those with poor ELP were less likely than those with good ELP to start smoking regularly before age 18 , smoke their first cigarette within 30 minutes, and have received advice to stop smoking from a health care provider in the past 12 months. First generation immigrants were less likely than second and third generation immigrants to report beginning smoking regularly before 18 years of age, have their first cigarette within 30 minutes, and report having received advice to stop smoking from a health care provider in the last 12 months.

Those with poor ELP were slightly less likely to be daily smokers than those with good ELP but were equally likely to be former smokers. First generation immigrants were less likely than third generation immigrants to be daily smokers, while they were more likely than second and third generation immigrants to be someday smokers.

3.3. Multivariable Models. Table 3 presents unadjusted odds ratios (UOR) based on univariable logit regressions and adjusted odds ratios (AOR) with $95 \%$ confidence intervals (CI) of making a quit attempt in the past year by ELP, immigrant generation, and control variables. Overall, those with poor ELP were more likely to have made a quit attempt relative to those with good ELP $(\mathrm{AOR}=1.22$, CI: 1.02-1.46) after controlling for demographic and smoking characteristics. Similarly, first (AOR $=1.21$, CI: $1.02-1.43$ ) and second generation immigrants $(\mathrm{AOR}=1.36, \mathrm{CI}: 1.12$ 1.64) were more likely than third generation or higher immigrants to have made a quit attempt in the past 12 months.

Table 4 presents the models with interactions for gender and ELP and gender and immigrant generation. The AOR 


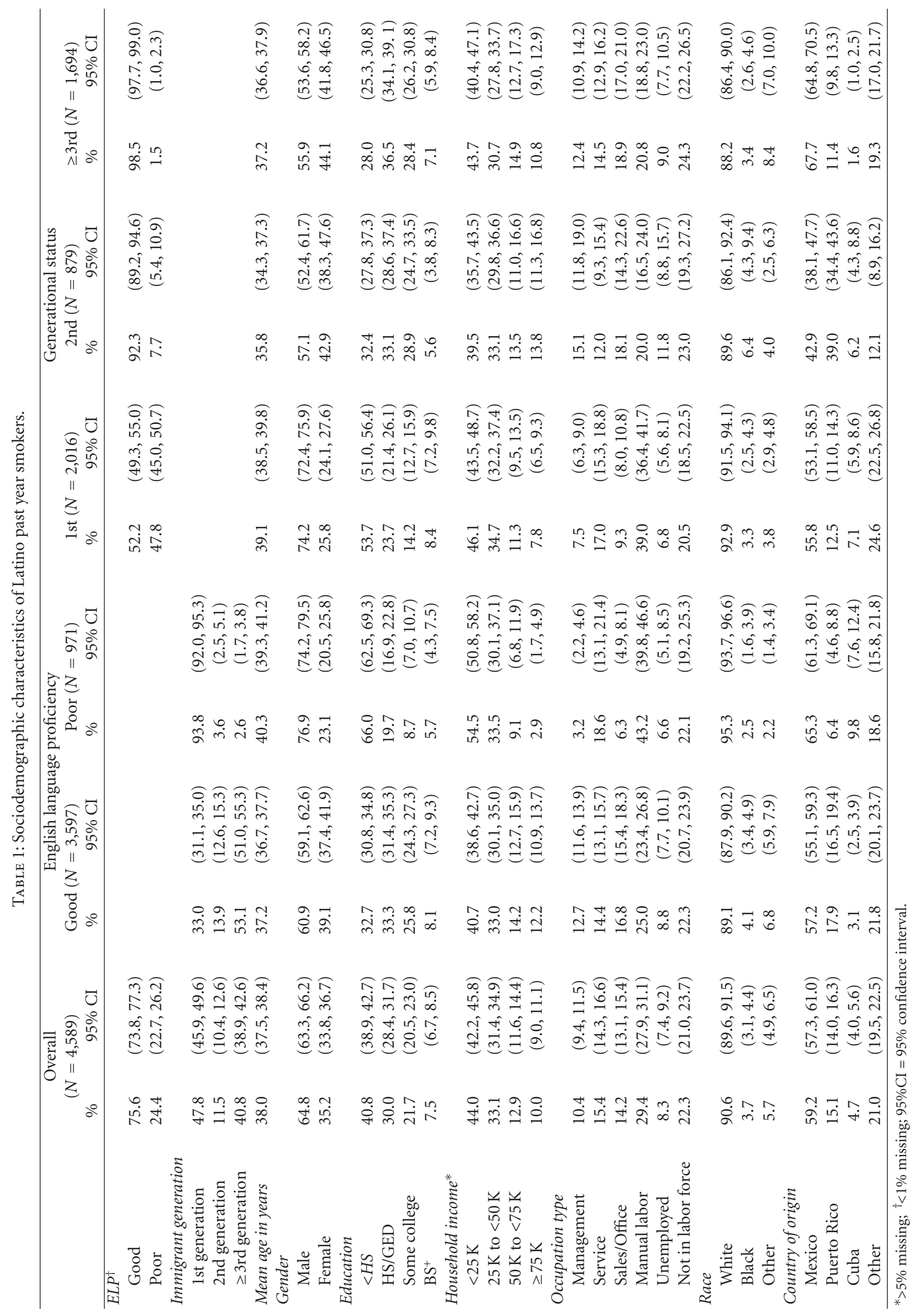




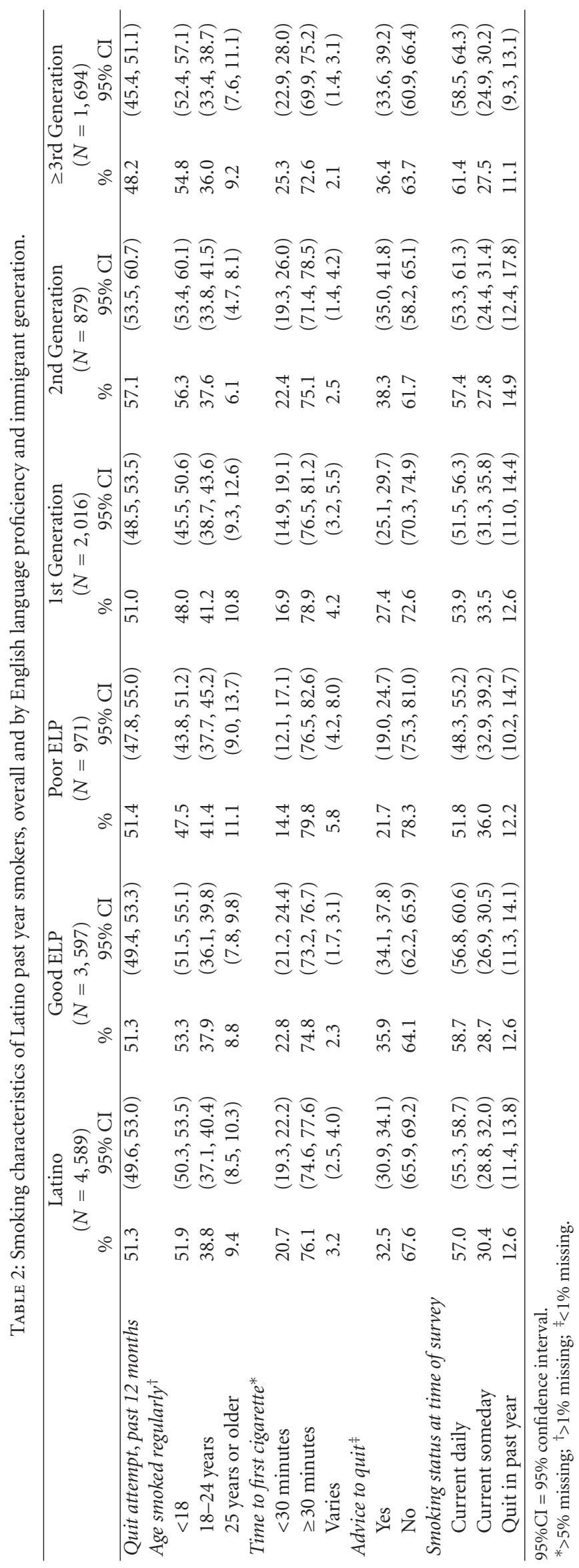


TABLE 3: Odds ratios for making a quit attempt in the past 12 months, by ELP, immigrant generation, and covariates $(N=4,589)$.

\begin{tabular}{|c|c|c|c|c|c|c|}
\hline & \multicolumn{2}{|c|}{$\begin{array}{l}\text { Univariable logit } \\
\text { regressions }\end{array}$} & \multicolumn{2}{|c|}{$\begin{array}{c}\text { Multivariable model: } \\
\text { English language proficiency }\end{array}$} & \multicolumn{2}{|c|}{$\begin{array}{l}\text { Multivariable model: } \\
\text { immigrant generation }\end{array}$} \\
\hline & UOR & $95 \% \mathrm{CI}$ & AOR & $95 \% \mathrm{CI}$ & AOR & $95 \% \mathrm{CI}$ \\
\hline \multicolumn{7}{|l|}{ ELP } \\
\hline Poor & 1.00 & $(0.85,1.18)$ & 1.22 & $(1.02,1.46)$ & & \\
\hline Good & 1.00 & Referent & 1.00 & Referent & & \\
\hline \multicolumn{7}{|l|}{ Immigrant generation } \\
\hline 1st generation & 1.12 & $(0.96,1.30)$ & & & 1.21 & $(1.02,1.43)$ \\
\hline 2nd generation & 1.43 & $(1.20,1.71)$ & & & 1.36 & $(1.12,1.64)$ \\
\hline$\geq 3$ rd generation & 1.00 & Referent & & & 1.00 & Referent \\
\hline \multicolumn{7}{|l|}{ Gender } \\
\hline Female & 1.00 & Referent & 1.00 & Referent & 1.00 & Referent \\
\hline Male & 0.87 & $(0.75,1.00)$ & 0.94 & $(0.81,1.09)$ & 0.94 & $(0.81,1.09)$ \\
\hline Per cap tob control exp & 1.01 & $(1.00,1.03)$ & 1.02 & $(1.00,1.03)$ & 1.02 & $(1.00,1.03)$ \\
\hline \multicolumn{7}{|l|}{ Race } \\
\hline White & 1.00 & Referent & 1.00 & Referent & 1.00 & Referent \\
\hline Black & 1.40 & $(0.96,2.04)$ & 1.39 & $(0.96,2.03)$ & 1.32 & $(0.90,1.94)$ \\
\hline Other & 0.90 & $(0.68,1.18)$ & 0.80 & $(0.61,1.06)$ & 0.82 & $(0.62,1.08)$ \\
\hline \multicolumn{7}{|l|}{ Age (centered) } \\
\hline Age & 0.98 & $(0.98,0.99)$ & 0.98 & $(0.97,0.99)$ & 0.98 & $(0.97,0.99)$ \\
\hline \multicolumn{7}{|l|}{ Age of initiation } \\
\hline$<18$ & 1.00 & Referent & 1.00 & Referent & 1.00 & Referent \\
\hline $18-24$ & 1.12 & $(0.97,1.28)$ & 1.12 & $(0.94,1.33)$ & 1.13 & $(0.95,1.34)$ \\
\hline $25+$ & 1.05 & $(0.82,1.34)$ & 1.26 & $(0.96,1.67)$ & 1.27 & $(0.96,1.67)$ \\
\hline Unknown & 0.41 & $(0.23,0.72)$ & 0.32 & $(0.15,0.68)$ & 0.36 & $(0.18,0.73)$ \\
\hline \multicolumn{7}{|l|}{ Age* age of initiation } \\
\hline $18-24$ *age & 1.00 & $(0.99,1.01)$ & 1.00 & $(0.99,1.01)$ & 1.00 & $(0.99,1.01)$ \\
\hline $25+*$ Age & 0.99 & $(0.97,1.01)$ & 0.99 & $(0.98,1.01)$ & 0.99 & $(0.97,1.01)$ \\
\hline Unknown *age & 0.99 & $(0.95,1.03)$ & 0.99 & $(0.93,1.04)$ & 0.99 & $(0.95,1.04)$ \\
\hline \multicolumn{7}{|l|}{ Education } \\
\hline$<$ High school & 0.83 & $(0.70,0.99)$ & 0.88 & $(0.74,1.05)$ & 0.90 & $(0.75,1.07)$ \\
\hline High school/GED & 1.00 & Referent & 1.00 & Referent & 1.00 & Referent \\
\hline Some college & 1.10 & $(0.91,1.32)$ & 1.04 & $(0.86,1.25)$ & 1.02 & $(0.85,1.23)$ \\
\hline$\geq$ Bachelor & 1.11 & $(0.85,1.46)$ & 1.01 & $(0.76,1.33)$ & 0.99 & $(0.75,1.31)$ \\
\hline \multicolumn{7}{|l|}{ Household income } \\
\hline$<25 \mathrm{~K}$ & 1.00 & Referent & 1.00 & Referent & 1.00 & Referent \\
\hline $25 \mathrm{~K}$ to $<50 \mathrm{~K}$ & 1.03 & $(0.87,1.22)$ & 0.95 & $(0.79,1.14)$ & 0.94 & $(0.78,1.12)$ \\
\hline $50 \mathrm{~K}$ to $<75 \mathrm{~K}$ & 1.06 & $(0.84,1.35)$ & 0.88 & $(0.70,1.12)$ & 0.87 & $(0.69,1.11)$ \\
\hline$\geq 75 \mathrm{~K}$ & 1.41 & $(1.07,1.86)$ & 1.24 & $(0.93,1.65)$ & 1.18 & $(0.89,1.57)$ \\
\hline Unknown & 0.83 & $(0.64,1.09)$ & 0.76 & $(0.56,1.02)$ & 0.76 & $(0.56,1.01)$ \\
\hline \multicolumn{7}{|l|}{ Time to first cigarette } \\
\hline$<30$ minutes & 1.00 & Referent & 1.00 & Referent & 1.00 & Referent \\
\hline$\geq 30$ minutes & 1.25 & $(1.06,1.47)$ & 1.20 & $(1.01,1.42)$ & 1.20 & $(1.01,1.44)$ \\
\hline Varies & 1.11 & $(0.72,1.71)$ & 1.15 & $(0.72,1.83)$ & 1.22 & $(0.77,1.93)$ \\
\hline Unknown & 17.00 & $(9.55,30.18)$ & 17.55 & $(10.11,30.48)$ & 17.93 & $(10.35,31.04)$ \\
\hline \multicolumn{7}{|l|}{ Advice from HCP } \\
\hline Yes & 1.41 & $(1.23,1.62)$ & 1.58 & $(1.36,1.83)$ & 1.55 & $(1.34,1.80)$ \\
\hline No & 1.00 & Referent & 1.00 & Referent & 1.00 & Referent \\
\hline Unknown & 0.85 & $(0.39,1.86)$ & 0.65 & $(0.22,1.91)$ & 0.64 & $(0.25,1.69)$ \\
\hline $\begin{array}{l}\text { Mean residual goodness } \\
\text { of fit statistic }\end{array}$ & & & $F_{(9,23}$ & $1, P>.05$ & $F_{(9,23}$ & $0, P>.05$ \\
\hline
\end{tabular}

$\mathrm{AOR}=$ adjusted odds ratio; $\mathrm{UOR}=$ unadjusted odds ratio; $95 \% \mathrm{CI}=95 \%$ confidence interval.

$\mathrm{ELP}=$ English language proficiency; $\mathrm{HCP}=$ health care provider. 
TABLE 4: Adjusted odds ratios for making a quit attempt in the past 12 months by ELP, immigrant generation, gender, and interactions for $\mathrm{ELP} *$ gender and immigrant generation $*$ gender $(N=4,589)$.

\begin{tabular}{|c|c|c|c|c|}
\hline & \multicolumn{2}{|c|}{ Multivariable model: English language proficiency ${ }^{\mathrm{a}}$} & \multicolumn{2}{|c|}{ Multivariable model: immigrant generation ${ }^{a}$} \\
\hline & AOR & $95 \% \mathrm{CI}$ & AOR & $95 \% \mathrm{CI}$ \\
\hline \multicolumn{5}{|l|}{ ELP } \\
\hline Poor & 1.47 & $(1.08,2.00)$ & & \\
\hline Good & 1.00 & Referent & & \\
\hline \multicolumn{5}{|l|}{ Immigrant generation } \\
\hline 1st generation & & & 1.35 & $(1.04,1.76)$ \\
\hline 2nd generation & & & 1.10 & $(0.84,1.44)$ \\
\hline$\geq 3$ rd generation & & & 1.00 & Referent \\
\hline \multicolumn{5}{|l|}{ Gender } \\
\hline Female & 1.00 & Referent & 1.00 & Referent \\
\hline Male & 0.99 & $(0.84,1.17)$ & 0.92 & $(0.73,1.16)$ \\
\hline \multicolumn{5}{|l|}{ Interactions } \\
\hline ELP $*$ gender & 0.78 & $(0.54,1.13)$ & & \\
\hline 1st generation $*$ gender & & & 0.86 & $(0.62,1.20)$ \\
\hline 2 nd generation $*$ gender & & & 1.43 & $(0.96,2.13)$ \\
\hline
\end{tabular}

${ }^{a}$ Controls for cumulative per capita tobacco control expenditures, race, education, income, time to first cigarette, cessation advice from healthcare provider, age, age of initiation, interaction of age and age of initiation.

$\mathrm{AOR}=$ adjusted odds ratio.

$95 \% \mathrm{CI}=95 \%$ confidence interval.

contrasting poor relative to good ELP is smaller by a factor of 0.78 (CI: 0.54-1.13) among males than among females. Similarly, the AOR contrasting 1st and 3rd generation immigrants is smaller by a factor of 0.86 (CI: $0.62-1.20$ ) among males than among females, and the contrast between 2nd and 3rd generation immigrants is larger by a factor of 1.43 (CI: 0.96-2.13) among males than among females.

Predictive margins for quit attempts by ELP and immigrant generation is presented in Figure 1. Latinos with good ELP $(50.3 \%)$ had lower predictive margin of past 12 month quit attempt than Latinos with poor ELP (54.8\%). First $(52.2 \%)$ and second generation immigrants $(54.9 \%)$ had higher predictive margins than third generation immigrant Latinos (47.9\%).

\section{Discussion}

The present analyses found that Latinos with poor ELP and those of a more recent immigrant generation were more likely to have made a quit attempt. Interestingly, third generation Latino immigrants had similar predictive margin of quit attempt as the overall non-Latino white estimate of quit attempts (46.4\%, data not shown in tables or figure). These findings are consistent with past research, which suggests that those with more exposure to USA culture adopt the prevailing tobacco behaviors, at least as compared to non-Latino whites, which is the comparison most often made in the tobacco control acculturation literature $[1,6$, $8-10,17]$. Our findings demonstrate that disaggregating Latinos based on language and immigrant generation are warranted in future studies of smoking cessation attempts.

The analysis did not find reliable evidence that that gender moderates the associations between quit attempts and

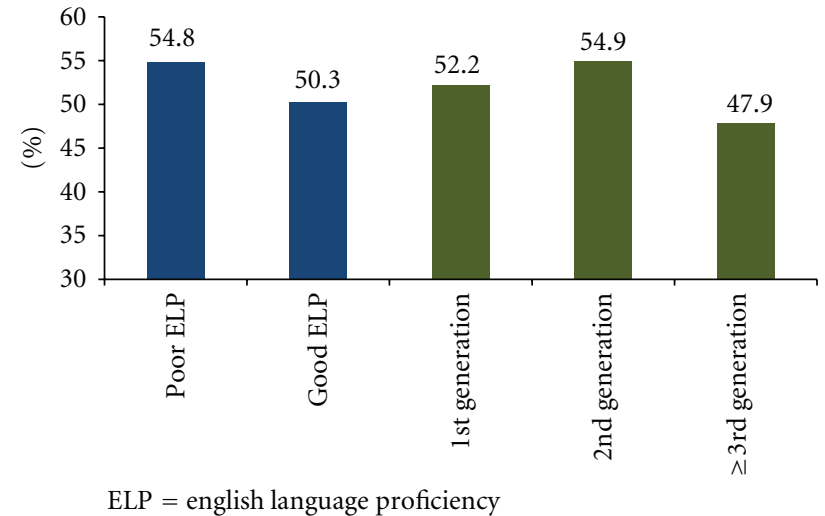

FIGURE 1: Predictive margins for making a quit attempt in the past 12 months by English language proficiency and immigrant generation among Latino past year smokers $(N=4,589)$. ELP $=$ English language proficiency.

ELP or immigrant generation. However, it is noteworthy that the direction of the interaction observed in these data is consistent with much of the research in the cigarette smoking literature in that there appears to be a stronger acculturation effect among women than there is among men $[2,4,5,9,12]$. In contrast, our findings are inconsistent with an analysis by Castro et al., who found an acculturation effect only among men and not among women [17]. Comparative population data has shown that the smoking prevalence in many Latin American countries is much lower compared to the USA rates among women but much more similar among men, and that has been the case over the last several years [43-45]. As such, the larger acculturation effect among females might be expected for smoking simply because there 
is more room for overt behavior change. However, there is little comparative population data from Latin American countries for cessation behaviors, which to an extent hinders interpretation of the findings from the present analysis. To date, only Mexico, through the Global Adult Tobacco Survey (GATS), has comparative population level cessation behavior data available [46]. The GATS data show that $57 \%$ of female past year smokers in Mexico had made a quit attempt compared to $47 \%$ among men [46]. This compares to $49 \%$ for females and $44 \%$ for males in the non-Latino white sample of the TUS-CPS (data not shown in tables). If the Mexico data roughly extend to other Latin American countries, it is consistent with acculturation to see a stronger association among women than among men for quit attempts. As comparative population level data become more widely available as global tobacco control surveillance grows, this information should be incorporated in future analyses to aid in interpretation of other tobacco use and cessation behaviors.

4.1. Strength and Limitations. The major strength of this paper is that it examined a relationship that has not previously been reported in the published literature. Moreover, it did so using a large nationally representative dataset with rich data on current and past tobacco behaviors and sociodemographic information on the Latino population. However, our paper also has some limitations. First, due to the cross-sectional design we do not have the longitudinal data to support conclusions about changes in smoking behavior patterns over time. Second, the analysis was limited by the variables that were available in the TUS-CPS dataset. As such, variables such as smoking cessation cognitions and other psychological measurements that may be related to cessation could not be controlled for. Third, the concept of acculturation involves multiple aspects to identity formation and adaptation that are inherently dynamic and complex. We used measures commonly applied in the literature, but in recent years Latino health researchers have increasingly called attention to the need for theoretically based measures of acculturation and studies that begin to capture the full range of the Latino experience in the United States, particularly socioeconomic and racially/ethnically-based disadvantage [16, 47-49]. Lastly, the data in the TUS are self-reported and are subject to recall error, which may be differential with respect to current versus former smokers and ELP or immigrant generation.

\section{Conclusion}

In summary, our study adds to the growing literature on the heterogeneity of Latino health and extends prior work by presenting data on quit attempts. These findings underscore the need to disaggregate Latinos beyond racial/ethnic categories to identify subgroup differences relevant for smoking and smoking cessation behaviors in this population.

\section{References}

[1] M. C. Acevedo, "The role of acculturation in explaining ethnic differences in the prenatal health-risk behaviors, mental health, and parenting beliefs of Mexican American and European American at-risk women," Child Abuse and Neglect, vol. 24, no. 1, pp. 111-127, 2000.

[2] D. Acevedo-Garcia, J. Pan, H. J. Jun, T. L. Osypuk, and K. M. Emmons, "The effect of immigrant generation on smoking," Social Science and Medicine, vol. 61, no. 6, pp. 1223-1242, 2005.

[3] P. J. Cantero, J. L. Richardson, L. Baezconde-Garbanati, and G. Marks, "The association between acculturation and health practices among middle-aged and elderly latinas," Ethnicity \& Disease, vol. 9, no. 2, pp. 166-180, 1999.

[4] J. Coreil, L. A. Ray, and K. S. Markides, "Predictors of smoking among Mexican-Americans: findings from the Hispanic HANES," Preventive Medicine, vol. 20, no. 4, pp. 508-517, 1991.

[5] R. T. Kimbro, "Acculturation in context: gender, age at migration, neighborhood ethnicity, and health behaviors," Social Science Quarterly, vol. 90, no. 5, pp. 1145-1166, 2009.

[6] G. Marin, E. Perez-Stable, and B. Vanoss Marin, "Cigarette smoking among San Francisco Hispanics: the role of acculturation and gender," American Journal of Public Health, vol. 79, no. 2, pp. 196-198, 1989.

[7] K. S. Markides, J. Coreil, and L. A. Ray, "Smoking among Mexican Americans: a three-generation study," American Journal of Public Health, vol. 77, no. 6, pp. 708-711, 1987.

[8] E. J. Pérez-Stable, A. Ramirez, R. Villareal et al., "Cigarette smoking behavior among US Latino men and women from different countries of origin," American Journal of Public Health, vol. 91, no. 9, pp. 1424-1430, 2001.

[9] J. Sundquist and M. A. Winkleby, "Cardiovascular risk factors in Mexican American adults: a transcultural analysis of NHANES III, 1988-1994," American Journal of Public Health, vol. 89, no. 5, pp. 723-730, 1999.

[10] A. V. Wilkinson, M. R. Spitz, S. S. Strom et al., "Effects of nativity, age at migration, and acculturation on smoking among adult Houston residents of Mexican descent," American Journal of Public Health, vol. 95, no. 6, pp. 1043-1049, 2005.

[11] D. V. Coonrod, H. Balcazar, M. J. Brady, S. Garcia, and M. van Tine, "Smoking, acculturation and family cohesion in Mexican-American women," Ethnicity \& Disease, vol. 9, no. 3, pp. 434-440, 1999.

[12] L. A. Palinkas, J. Pierce, B. P. Rosbrook, S. Pickwell, M. Johnson, and D. G. Bal, "Cigarette smoking behavior and beliefs of Hispanics in California," American Journal of Preventive Medicine, vol. 9, no. 6, pp. 331-337, 1993.

[13] J. M. Samet, C. A. Howard, D. B. Coultas, and B. J. Skipper, "Acculturation, education, and income as determinants of cigarette smoking in New Mexico hispanics," Cancer Epidemiology Biomarkers \& Prevention, vol. 1, no. 3, pp. 235-240, 1992.

[14] J. W. Bethel and M. B. Schenker, "Acculturation and smoking patterns among Hispanics: a review," American Journal of Preventive Medicine, vol. 29, no. 2, pp. 143-148, 2005.

[15] G. R. VandenBos, American Psychological Association. APA Dictionary of Psychology, American Psychological Association, Washington, DC, USA, 1st edition, 2007.

[16] L. J. Cabassa, "Measuring acculturation: where we are and where we need to go," Hispanic Journal of Behavioral Sciences, vol. 25, no. 2, pp. 127-146, 2003.

[17] Y. Castro, L. R. Reitzel, M. S. Businelle et al., "Acculturation differentially predicts smoking cessation among Latino men and women," Cancer Epidemiology Biomarkers \& Prevention, vol. 18, no. 12, pp. 3468-3475, 2009.

[18] M. C. Fiore, C. R. Jaen, and T. B. Baker, Treating Tobacco Use and Dependence: 2008 Update, Rockville Md, USA. 
[19] United States Deptartment of Health and Human Services, Tobacco Use Among U.S. Racial/Ethnic Minority Groups, Deptartment of Health and Human Services, Center for Disease Control and Prevention, National Center for Chronic Disease Prevention and Health Promotion, Office on Smoking and Health, Atlanta, Ga, USA, 1998.

[20] E. K. Burns, A. H. Levinson, D. Lezotte, and A. V. Prochazka, "Differences in smoking duration between Latinos and Anglos," Nicotine and Tobacco Research, vol. 9, no. 7, pp. 731-737, 2007.

[21] A. Hyland, Q. Li, J. E. Bauer, G. A. Giovino, C. Steger, and K. M. Cummings, "Predictors of cessation in a cohort of current and former smokers followed over 13 years," Nicotine and Tobacco Research, vol. 6, supplement 3, pp. S363-S369, 2004.

[22] N. Hymowitz, K. M. Cummings, A. Hyland, W. R. Lynn, T. F. Pechacek, and T. D. Hartwell, "Predictors of smoking cessation in a cohort of adult smokers followed for five years." Tobacco Control, vol. 6, supplement 2, pp. S57-S62, 1997.

[23] C. W. Lee and J. Kahende, "Factors associated with successful smoking cessation in the United States, 2000," American Journal of Public Health, vol. 97, no. 8, pp. 1503-1509, 2007.

[24] P. Fagan, E. Augustson, C. L. Backinger et al., "Quit attempts and intention to quit cigarette smoking among young adults in the United States," American Journal of Public Health, vol. 97, no. 8, pp. 1412-1420, 2007.

[25] E. J. Perez-Stable, F. Sabogal, G. Marin, B. V. Marin, and R. Otero-Sabogal, "Evaluation of 'Guia para Dejar de Fumar,' a self-help guide in Spanish to quit smoking," Public Health Reports, vol. 106, no. 5, pp. 564-570, 1991.

[26] B. C. Bock, R. S. Niaura, C. J. Neighbors, R. Carmona-Barros, and M. Azam, "Differences between Latino and non-Latino White smokers in cognitive and behavioral characteristics relevant to smoking cessation," Addictive Behaviors, vol. 30, no. 4, pp. 711-724, 2005.

[27] J. C. Day, Population Projections of the United States by Age, Sex, Race, and Hispanic Origin: 1995 to 2050, U.S. Government Printing Office, Washington, DC, USA, 1996.

[28] R. Suro, R. Kocchar, J. Passel et al., The American CommunityHispanics: 2004. American Community Survey Reports, United States Census Bureau, 2007.

[29] D. Acevedo-Garcia, E. Barbeau, J. A. Bishop, J. Pan, and K. M. Emmons, "Undoing an epidemiological paradox: the tobacco industry's targeting of US immigrants," American Journal of Public Health, vol. 94, no. 12, pp. 2188-2193, 2004.

[30] U.S. Census Bureau, Census, 2010.

[31] U.S. Department of Commerce, Census Bureau 2006, National Cancer Insitute, Centers for Disease Control and Prevention co-sponsored Tobacco Use Special Cessation Supplement to the Current Population Survey 2003, http://riskfactor.cancer.gov/studies/tus-cps.

[32] U.S. Department of Commerce, Census Bureau 2006, National Cancer Insitute, Centers for Disease Control and Prevention, "Current population survey, May 2006, August 2006, and January 2007: tobacco use supplement," Technical Documentation.

[33] U.S. Department of Commerce, Census Bureau 2006, National Cancer Insitute, Centers for Disease Control and Prevention, "Current population survey, February, June, and November 2003: tobacco use supplement," Technical Documentation.

[34] U.S. Department of Labor, Bureau of Labor Statistics, U.S. Department of Commerce, Economics and Statistics Administration, U.S. Census Bureau, Current Population Survey Technical Paper 63RV: Design and Methodology, 2002.
[35] T. H. Cruz, S. W. Marshall, J. M. Bowling, and A. Villaveces, "The validity of a proxy acculturation scale among U.S. Hispanics," Hispanic Journal of Behavioral Sciences, vol. 30, no. 4, pp. 425-446, 2008.

[36] M. C. Farrelly, T. F. Pechacek, and F. J. Chaloupka, "The impact of tobacco control program expenditures on aggregate cigarette sales: 1981-2000," Journal of Health Economics, vol. 22, no. 5, pp. 843-859, 2003.

[37] M. C. Farrelly, T. F. Pechacek, K. Y. Thomas, and D. Nelson, "The impact of tobacco control programs on adult smoking," American Journal of Public Health, vol. 98, no. 2, pp. 304-309, 2008.

[38] D. W. Hosmer and S. Lemeshow, Applied Logistic Regression, Wiley, New York, NY, USA, 2nd edition, 2000.

[39] E. Norton, H. Wang, and C. Ai, "Computing interaction effects and standard errors in logit and probit models," The Stata Journal, vol. 4, no. 2, pp. 103-116, 2004.

[40] C. Ai and E. C. Norton, "Interaction terms in logit and probit models," Economics Letters, vol. 80, no. 1, pp. 123-129, 2003.

[41] StataCorp LP, Stata Survey Data Reference Manual: Release 11, L. P. StataCorp, College Station, Tex, USA, 2009.

[42] N. Schenker and J. F. Gentleman, "On judging the significance of differences by examining the overlap between confidence intervals," The American Statistician, vol. 55, no. 3, pp. 182186, 2001.

[43] J. Mackay, M. P. Eriksen, and O. Shafey, American Cancer Society. The Tobacco Atlas, American Cancer Society, Atlanta, Ga., USA, 2006.

[44] J. Mackay and M. P. Eriksen, World Health Organization. The Tobacco Atlas, World Health Organization, Geneva, Switzerland, 2002.

[45] O. Shafey, American Cancer Society. The Tobacco Atlas, American Cancer Society, Atlanta, Ga, USA, 2009.

[46] L. M. R. Shigematsu, T. S. Levy, I. M. Gómez-Humarán, and R. R. Martínez, Encuesta Global de Tabaquismo en Adultos, México 2009, Cuernavaca, México, 2010.

[47] A. F. Abraído-Lanza, A. N. Armbrister, K. R. Flórez, and A. N. Aguirre, "Toward a theory-driven model of acculturation in public health research," American Journal of Public Health, vol. 96, no. 8, pp. 1342-1346, 2006.

[48] A. Portes, P. Fernández-Kelly, and W. Haller, "Segmented assimilation on the ground: the new second generation in early adulthood," Ethnic and Racial Studies, vol. 28, no. 6, pp. 10001040, 2005.

[49] R. E. Zambrana and O. Carter-Pokras, "Role of acculturation research in advancing science and practice in reducing health care disparities among latinos," American Journal of Public Health, vol. 100, no. 1, pp. 18-23, 2010. 


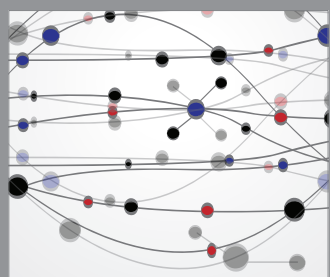

The Scientific World Journal
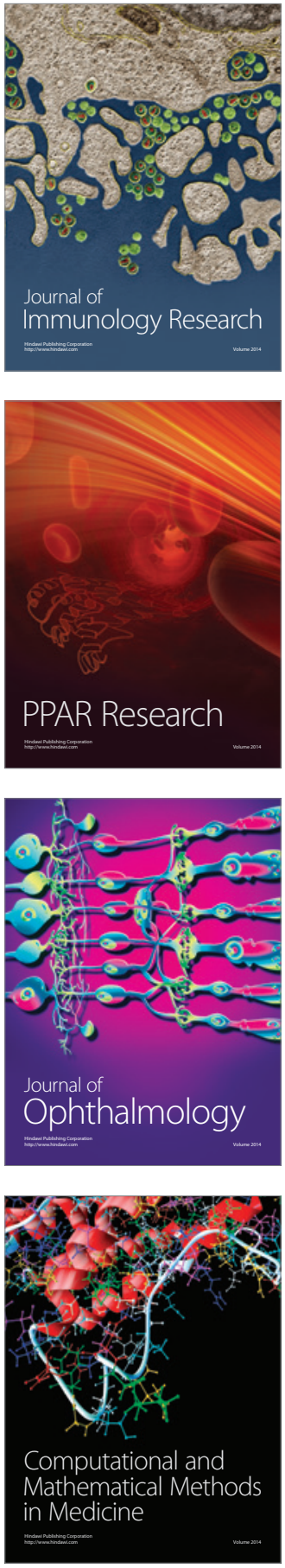

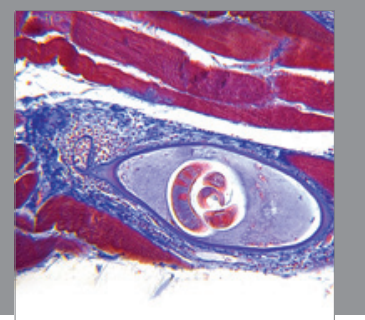

Gastroenterology

Research and Practice
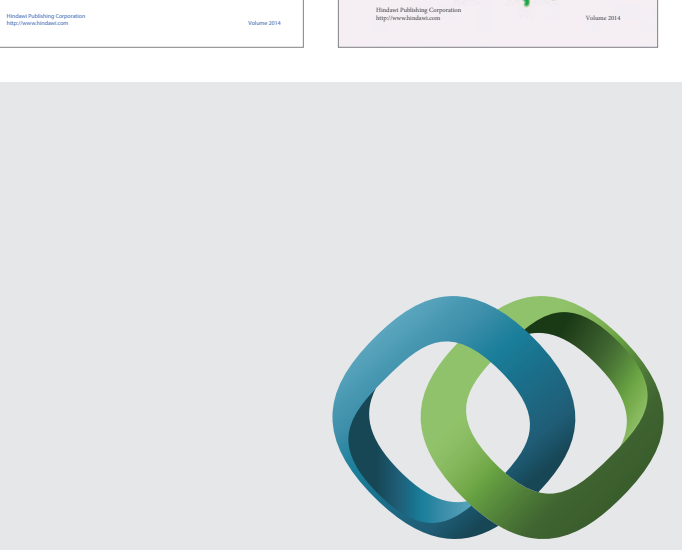

\section{Hindawi}

Submit your manuscripts at

http://www.hindawi.com
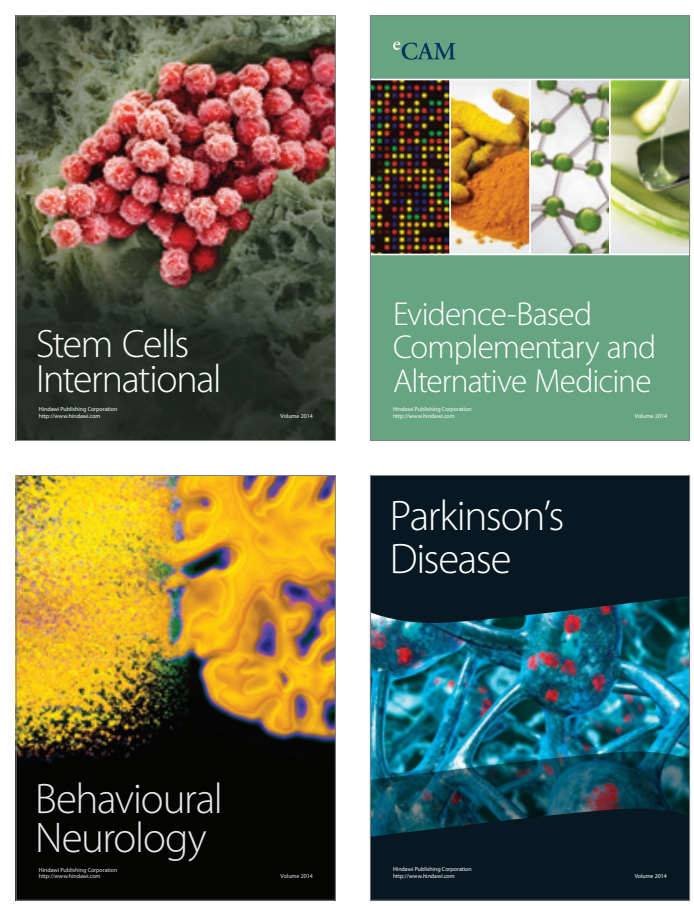

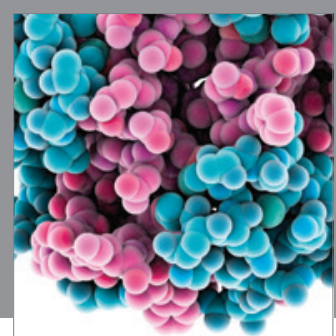

Journal of
Diabetes Research

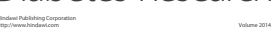

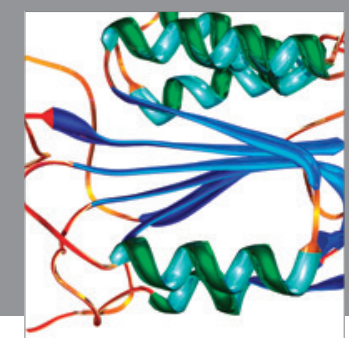

Disease Markers
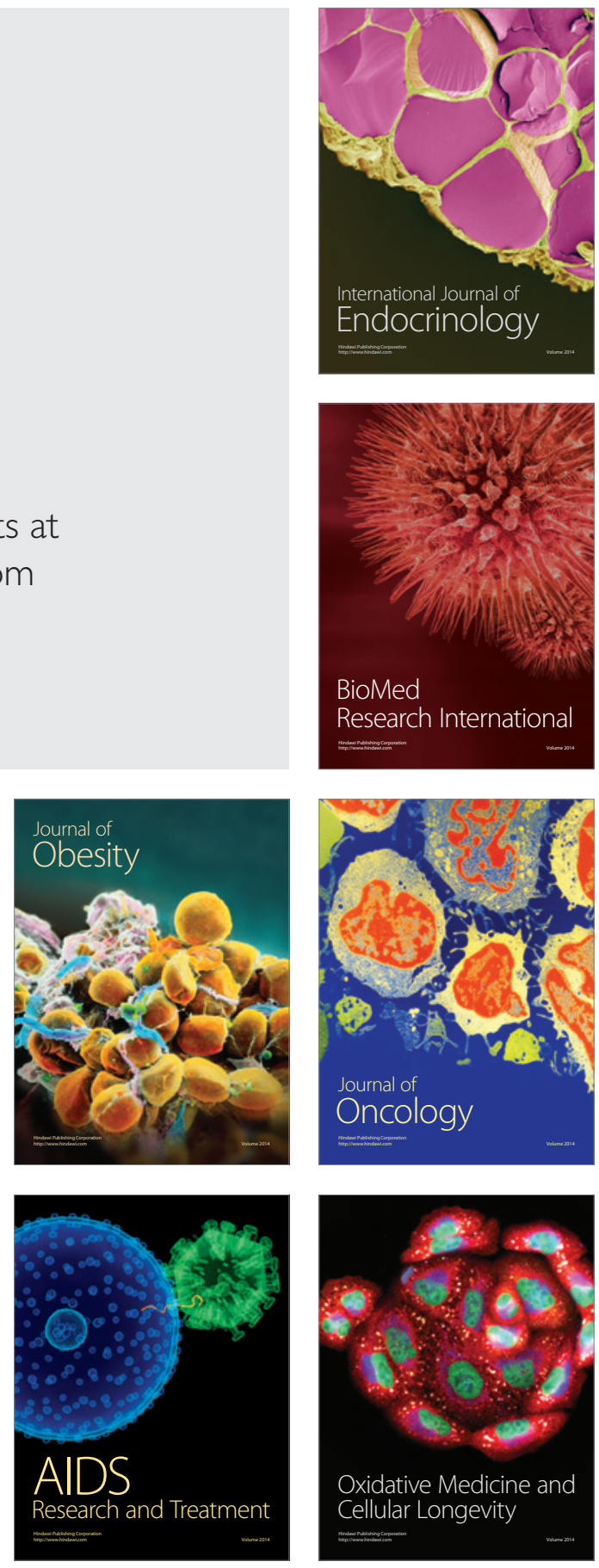